\title{
Exploring the Logic of Name Changes and Identity Construction: A Reflective Self-Narration of Assimilation Expectations
}

\author{
XING XU
}

School of International Relations, Sichuan International Studies University, Chongqing, P.R. China; School of Education, University of Newcastle, Newcastle, Australia

This paper derives largely from my own experience during two international sojourns as a case study to tease out the salient elements of the dynamic processes involved in the exchange of my Chinese name Xing for an arbitrary English counterpart Helen, and then followed by reverting to Xing again. Contrary to previous studies that construe the issues of international students reconstructing their ethnic names into English ones as an innocuous expression of good will and cultural integration, this study argues that the neglected impact that these transitions of nomenclature have on the patronization of one's ethnic identity should be addressed as a matter of significant importance. The methodological approach taken here will involve adopting a reflective philosophical self-narration of the ramifications on my ethnic identity associated with the name change. This analysis will be extrapolated and further developed within Cross's five-stage model, arguing that the name change process is indicative of a developing awareness of one's ethnic identity.

KEYWORDS cultural assimilation, Chinese names/English names, international student pressure, name changes, ethnic identity. 


\section{Introduction}

\section{English name usage for Chinese students}

In traditional Chinese culture, people attach great significance to names whose importance transcends the concept of being a mere referential linguistic token. Instead, Chinese birth names reflect ancestral elements of heritage and are to be construed as active, creative, and efficacious semiotic resources (Henry 20I2). Closely linked to the expression of heritage identity or hopes at various levels, Chinese names can manifest a hybrid concept such as, "In a name there is often imprinted a code that identifies us as belonging to a sex, a social class, a political or religious creed, a geographical place, or a race" (Quaglia et al. 2016, 291).

In an increasingly interconnected world where English is the lingua franca, many schools in China have introduced English-language classes, wherein English names are either bequeathed to students by a teacher or self-selected by students (Henry 20I2). By English names, those adopted within this context are not necessarily commonly used in, or always originated in, England. They are not so much chosen for having an English etymology, but are designated as sounding English. For example, Chinese male and female students respectively sometimes choose a name whose etymology stretches back to Hebrew or ancient Greek origins such as Joseph or Helen whose etymology has long since been forgotten by the English themselves, let alone by visiting Chinese students. Amidst the dearth of research on the reasons behind the adoption of English names for Chinese students, a few studies have revealed a pragmatic orientation, such that the appropriation of an English name can be exploited to diminish the hierarchical disparity of power that characterizes the relationship between Chinese students and their Englishspeaking hosts (Edwards 2006). Within this context, the acquisition of an English name can also feature as an impetus for motivating students to communicate more frequently in English (Chien 20I2). Heffernan (20I0) is another researcher who reports a culturally driven incentive for such practices as these. The author finds that the concept surrounding the term "language desire" created by Piller (2002) persuasively affords a substantial measure of explanatory power. For example, among many students of Asian origin, there exists a favorable emotional disposition toward gaining a reasonable mastery of the English language. The bestowal of an English name on Chinese students can thus be construed as a legitimated strategy capable of affording an opportunity to satisfy their desire for Yangqi "exoticism", and to achieve a distinguishable Shenfen "status", both of which are idealistic acquisitions associated with the cultural dimensions embedded in the English language itself. This view is echoed by McPherron, who argues that name choices for ethnic students exemplify the "imagination of an international community in English, wherein certain cultural habits are valued, including having an English or non-Chinese name" $(2009,524)$. This view is further elaborated when scholars (Henry 20I2; Li I997; Sercombe et al. 20I4) contend that the appropriation of nonheritage names among Chinese students is a prerequisite if they are to succeed in claiming their membership within the English-speaking community in which they study. 


\section{Surrogate names and marginalization of ethnic identity}

The foregoing literature reveals some of the multifaceted reasons and a tolerably coherent rationale why Chinese students are willing to accept an English name. Despite the academic integrity of the discourse surrounding this point, there is no study, to the author's knowledge, that has satisfactorily investigated the adverse ramifications that the adoption of English names has had on Chinese heritage identity, the dynamics of which have resulted in the deprecation and diminution of a person's Chinese ethnic identity. Indeed, the etiology of my research preoccupation with the disposition of relinquishing one's ethnic name for the primary purpose of appropriating endearing English names relates to the impact that I contend the process of nominal surrogacy creates as an impediment to the preservation of one's ethnic sociocultural identity. Employing an ethnographic research method that is grounded in an epistemology of reflective self-narration, coupled with the adoption of Cross's (I97I) five-stage model of identity, I shall argue that the extent to which ethnic identity is being threatened in this context has for the most part been neglected. The feeling of being covertly coerced to acquire an English name for facilitating one's assimilation into an anglophone culture leads ineluctably to a much deeper issue than has yet been recognized concerning the marginalization of one's ethnic identity.

\section{Study}

\section{A reflective self-narration of a critical incident: the research method}

Narrative has long been a hermeneutic tool employed by qualitative researchers to gain insight into how humans understand and enact their lives through stories (Sandelowski I99I), illuminating the intersection of biography, history and society (Riessman 200I). Self-narration as a way to narrate oneself provides readers with the authentic subject of the writer, but also with the cultural and historical world that the writer inhabited and of which the writer might still be an inhabitant (Chik 20I0). For readers who can empathize with what the writer narrates, there is a spatial and temporal nexus that connects the writer and readers. It is the connection magnifying something personal to an emergent property beyond the personal that marks a "private act of self-writing" (Gunn I982, 8) transforming shared moments of rumination into a cultural act of collaborative reading.

The Critical Incident Technique has been applied widely in qualitative research. A critical incident is defined as:

... a story with a climax, dilemma or issue to be addressed, but no clear resolution and when

the incident is finished being told, there is still a need to ascribe some meaning to the incident

before it can be resolved in the mind of the teller. (Fitzgerald 200I, I5I)

A critical incident provides a running experiential commentary of meaningful events and reactions to those events (Brookfield I995). It is capable of yielding rich and contextualized data that reflect real-life experiences, thus providing insights into how and why people engage in the activity (Hughes, Williamson, and Lloyd 2007).

The nature of the study fits in well with a reflective self-narration of a critical incident. As the author self-narrates a critical incident of name change in a reflective manner, she empathizes with overseas students who may share the same experience. This empathetic 
connection turns a personal story into a phenomenon with a wider moral significance that deserves additional scholarly exploration.

\section{A reflective self-narration of a critical incident: the story}

A guy beaming with smiles approached me at the orientation for research students at the University of X saying, "Hello, I am James. Glad to meet you. By the way, what's your name?" "Nice to meet you too. I am Xing", I responded.

"Sorry, can you repeat that?" the guy asked, looking dumbfounded.

"My name is Xing. X-I-N-G. I presume you find it a bit difficult to pronounce, right? It's a Chinese name", I explained.

"Well, I see. Nice name. But don't you have any English name? Seems all Chinese students I have met here have one.” James looked more curious and puzzled.

"This is my name, and I don't have any second name. Xing is my given name, which means lucky in Chinese", I replied with a keen interest in elaborating more.

"Sounds interesting. Nice to meet you Xing", James said while walking off.

This is a genuine snapshot of my first encounter with a doctoral student in Australia. For the past six months, the memory of the incident has been lingering as I ponder occasionally why I prevaricated by telling James that I do not have any English name. The truth is that I did have one - Helen - a randomly self-arranged English name which I used wherever an "exotic" interaction is enacted, ranging from English classes in China, daily communications with English speakers, and my one-year study in the UK. But since my return after graduation, Helen has literally vanished from my life with the re-adoption of my Chinese name Xing, as required by the mainstream norm in working, familial, and social settings. It seems that Helen and all marks enshrined within that name have become increasingly foggy until they have at last faded into a once-upon-a-time UK memory.

Interestingly, history repeats itself. Six years later, I refer to myself as a migratory bird who flew to the Southern Hemisphere seeking a PhD education, as Xing not Helen. A sense of nonattachment and repulsion toward Helen prevails, justifying my response in the encounter with James. I have a hint that Xing is the only name that I would ever accept being known by. If I am fine with Helen, why not Judy, Jasmine, or Jade? None of them makes a difference to me anyway, as none can represent my identity, which is, and should only be, Xing.

In the author's personal case, the appropriation of a common host name without any embedment of personal history has been experienced as a transformational compromise and marginalization of Chinese identity; a process that many international students may undergo without understanding why they feel disoriented and culturally lost. One vital consideration of this paper is to shed more light on how the process of coerced relinquishment of an ethnic person's heritage name is tantamount to an acute disruption of the development of one's ethnic identity.

\section{Theoretical framework: five-stage model of identity development}

Names have long been recognized as being closely related to ethnic identity (Harrison I999). Name changes could thus be explored in terms of the development of ethnic 
identity. Researchers have addressed the issue of identity development as a modality of sequenced stages (Arce I98I; Cross I978; Kim I98I). Cross's five-stage model features prominently as one of the most efficacious proposals. Although the theory initially aims to explore the process of becoming Black, as it relates to African Americans, it affords a framework applicable to other ethnic groups. Previous research has shown that the process of identity development shares similarities between other ethnic minority groups and African Americans (Highlen et al. I988; Phinney 1990).

According to Cross (I97I), the progression of the five stages can be presented as follows: (a) pre-encounter, (b) encounter, (c) immersion/emersion, (d) internalization, and (e) internalization-commitment. In the pre-encounter stage, individuals are unaware of ethnic membership, demonstrating a disinterest in what in-groupness means. This stage is followed by the encounter stage where traumatic events or any event exerting a personally significant impact on change in thinking (Cross I995) is acknowledged, galvanizing an awakening of ethnic awareness. In the third stage of immersion/emersion, individuals embrace in-groupness by fully immersing themselves as a member, which is then followed by the internalization stage in which individuals are comfortable with a strong sense of ethnic identity. The final stage is featured by obtaining a healthy ethnic identity, which, according to Constantine et al., means "Blacks ... end up with internalized positive feelings about themselves, other Blacks, and other racial groups" ( 1998,96$)$.

Briefly, Cross argues for the development of ethnic identity commencing with individuals being unaware of or disinterested in what it means to claim a membership within a specific ethnic group. The awareness and interest are then stimulated by external factors, motivating individuals to navigate an exploration into their ethnicity. Ideally, after this stage, there should be a sense of ethnic membership ready to be cultivated, where individuals become comfortable with their in-groupness, such that a positive group-esteem is produced, along with a joint commitment to elevating the ethnic status as a whole.

The idea enshrined in this model was that ethnic identity is a becoming rather than a being, the formation of which involves an identity crisis, a search, an exploration, and a commitment (Phinney I989), each of which resonates with the author's personal experience of ethnic identity development entrenched in the concept of name change. The next part delves into an analysis of this experience within the theoretical lens.

\section{Discussion: name change and identity development}

\section{First sojourn: the adoption of Helen and a weak ethnic identity}

As a sojourner residing abroad where the meaning construction of the previous identity label is missing, the tension between a spatial discontinuity and a temporal continuity from one's past will lead to a negotiation of how one's identity is to be presented in a new environment. In my case, upon arrival and throughout the first sojourn, I continued the usage of Helen, which embodied a weak perception of my ethnic identity, combined with a pragmatically assimilated intention.

My first sojourn finds me in what Cross calls the pre-encounter stage. Ablaze with the excitement of studying overseas, I fancy everything "British", including an English name, while ignoring anything Chinese, giving no thought whatsoever about my ethnic membership. This view of weak ethnic identity is accompanied by an eagerness to assimilate into the host environment in which I intuitively conjecture that the use of my English 
name functions as a prerequisite for a proper induction and growing socialization. Fearing a Chinese heritage name would make myself a cultural misfit, I was determined to erase the trace of my origin in order to assimilate (Aoki 20I2), and the adoption of Helen over Xing is the tool I used. As Tournier asserts, “To change one's name is to break one's continuity as a person, to cut oneself off from the whole of one's past, which has defined one's person up to that point" (I975, I9). By embracing the name Helen in the UK, I had hoped to establish a new "international" identity by means of language socialization. Baquedano-López and Kattan argue that “... (through language) younger or newer members of communities are socialized to the beliefs and sociocultural and linguistic practices of their communities, ... while also being socialized to community-specific ways of using language" $(2007,74)$. As a visible ethnic minority, abandoning a Chinese-sounding name and adopting an English counterpart was an approach to establishing a membership status in an English community through engagement in the shared practice of sounding English, a compliance with Communities of Practice (Lave and Wenger 199I). Since names are indicative of constructing boundaries of belonging and demarcating who is an insider and who is an outsider (Alia 2007), the adoption of the English name Helen was a commentary on my intention of minimizing otherness, which served as a purposeful assimilation signal manifested by concealing my Chinese origin and displaying my newly adopted English orientation (Goldstein and Stecklov 20I6).

\section{Second sojourn: the adoption of Xing and a strong ethnic identity}

International students uprooting themselves from their home, culture, and social categories of neighborhood, family, and nation represent much of what they were once connected to but, in the context of their host culture, are unwittingly or intentionally lost (Rosenblum, Haines, and Cho 20I6). My adoption of Helen cuts off the established relationship between Xing and every identity built upon this label, such as the membership of my family and Chinese nationality, such that the severance was a form of disconnectedness. After graduation and my endeavor to re-assimilate into Chinese culture, the shift from one name to another entailed confusion and separation. There was a veritable cultural split and discontinuity between the two worlds of host and ethnic community (Yoon et al. 20I7). This painful experience is much akin to the second stage encounter - which provokes my repulsion toward the fuzziness, discontinuity, and chaos resulting from reconnection, so I decided to avoid using Helen. In this sense, my name change represented a pragmatic consideration of retaining the cultural capital of China.

Further, the discomfort toward and suspicion of James's take-for-granted statement that all Chinese in English-speaking environments have an English name signals an "aha moment" in my thinking as to who I really am and the person I want others to know me as. Do I have to be Helen to be accepted as a legitimate member? Should I feel ashamed about disclosing my Chineseness by a heritage name? Rather than considering my ethnic background as a fundamental flaw, I decided to empower myself by claiming ownership of a shared identity of international student without feeling that assimilation will be diminished if my ethnic background is exposed by my ethnic name (Edge 2010). By this stage, which is termed immersion/emersion, a strong sense of the self-awareness of my identity as Xing re-emerged. Thus, this change of name reflected a renewed sense of self-direction and ethnically identified pride (Emmelhainz 20I2). I have not only come 
to terms with, but also fully immersed myself in, building my role as a member of the Chinese ethnic minority.

Ever since my brief acquaintance with James, I have kept introducing myself as Xing on all occasions, explaining repetitively its pronunciation, spelling, and significance referring to Chinese naming practice. In this way, not only do I make my invisible Chinese identity in Helen public with ease, but also I emphasize and consolidate my ethnic identity with pride. In hindsight, by internalizing my otherness as Chinese, I gradually nurture an ethnic identity with a commitment to affiliate psychologically to my ethnic group and heritage (Fuller-Rowell, Ong, and Phinney 20I3) and finally construct a healthy ethnic identity, by which I can see my in-group and out-groups from a more open-minded, inclusive, and egalitarian perspective.

\section{A comprehensive reflection on the first and second sojourn}

Transplanting Cross's theory of identity development based on African Americans to the foregoing analysis of my personal experience of name change as a Chinese student studying in an anglophone culture reveals that the dynamic processes involved in my name change are suggestive of the fluidity of my ethnic identity development as illustrated in these five stages. The first sojourn witnessed the exchange of my Chinese name Xing for an English counterpart, Helen, driven by my need for assimilation. As a result of my weak ethnic identity, my rejection of the English name in the second sojourn represents an invalidation of "linguistic imperialism at the level of names" (Edwards $2006,97)$ where one automatically or forcibly complies with the perceived expectation of adopting an anglophone name to strip one's otherness. By claiming my heritage name, I also reclaimed my submerged ethnic identity that would otherwise remain obscured by an English name. The reclamation of Xing embodies a stronger awareness of my ethnic identity. As is elucidated in detail in the preceding parts, my personal experience instantiates the feasibility of a novel application of Cross's theoretical model to a personal case in a culturally distant context. This interpretation exemplifies Ruiz's (I999) argument that Cross's model is a guide to exploration into other cultural or ethnic minority identity constructions.

\section{Conclusions}

Identity is subject to variations that occur longitudinally during one's life course (Pietikäinen and Dufva 2006), and its formation is always incomplete, unstable, and discursive in nature (Hannah 20I5). For international students situated in a transnational nexus, their identity formation is complicated as they rely on mercurial identities that give glimpses of who they are and who they want to be. In essence, they endeavor to balance the sociocultural scales between two quite diverse cultures, peculiarly in tension with one another. Contrary to an essentialist view, identity is performative in the sense that it is involved in a form of circular and self-producing activity (Pennycook 2004), which is equally framed by prescribed traits and ongoing role-performing. My name change illustrates the variability of my construction of identity shaped by my adapting to the conventional rules set for my role as a minority in an English-speaking milieu. In the meantime, I argue for a caution of a total context-independent identity constructionist 
view, where self is "engulfed, if not annihilated" (Dunne I995, I40). The individual subjectivity emerges insofar as individuals understand themselves through narratives in which they engage themselves in the process of creating themselves (Crossley 2000). My experience contradicts postmodernist commentators by elucidating how individual subjectivity transforms into self-agency to maintain the "rooted" character of identity based on ethnicity, nationality, and language acquisition (May 200I). I further contend that there exists a reinforcing effect of external contexts on inner subjectivity insofar as "ethnically rooted" identity might be magnified rather than diminished when a sense of outsideness makes one more conscious of our cherished insideness. Transnational experience can heighten the awareness of ethnic identity, demonstrated by a sense of patriotism or nostalgia, a deeper appreciation for home arts, a more intense flavor of home dietary choice, or, as in my case, a fondness of an ethnic name.

Having situated my analysis within Cross's five-stage model, this study utilizes my own experience during two international sojourns to tease out the conflicting elements that can impact on the dynamic processes of ethnic identity development. This sociocultural tension has been brought to bold relief in the substitution of my Chinese name Xing for an arbitrary English counterpart Helen, followed by reversion to Xing again. While trading in my birth name to procure an English counterpart, I initially felt that the change of name represented an innocuous expression of good will and an effective segue for my cultural integration. However, the incident with James and my increasing reflections on the extent to which my ethnic identity was being compromised by my own efforts to pacify my host culture inevitably galvanized my decision to initiate the reclamation of my ethnic name, Xing.

The explanations and reasons why this "Relinquishment of Ethnic-Names-Ritual" occurs are complex and varied, but the dominant presumption is that by adopting an anglophone name, it makes it easier for ethnic minorities to become assimilated into the institutions where they study. My radical departure from my anglophone orientation was undergirded by the recognition of my naivety, lack of insight, identity crisis, search for meaning, and purposive commitment, as elucidated within Cross's model. In concluding this paper, let me restate that I have discovered myself, and I am pleased to be Xing and not Helen. Although I am still enamored with many things of anglophone character, not one of these things is worth changing my name to Helen.

\section{Disclosure statement}

This work is supported by the CSC-Newcastle University joint scholarship.

\section{Bibliography}

Alia, Valerie. 2007. Names and Nunavut: Culture and Identity in Arctic Canada. Oxon: Berghahn Books.

Aoki, Kayoko. 20I2. "Name and Ethnic Identity: Experiences of Korean Women in Japan." Journal of Asian and African Studies 47, no. 4: 377-391.

Arce, Carlos H 198I. "A Reconsideration of Chicano Culture and Identity.” Daedalus Iıo, no. 2: I77-I92.

Baquedano-López, P., and Shlomy Kattan. 2007. "Growing up in a Multilingual Community: Insights from Language Socialization." In Handbook of Multilingualism and Multilingual Communication, edited by Peter Auer and Li Wei, 69-100. Berlin: Mouton de Gruyter.

Brookfield, Stephen D. 1995. Becoming a Critically Reflective Practitioner. Thousand Oaks, CA: Sage. 
Chien, Grace Chin-Wen. 20I2. "Elementary School EFL Learners' Adoption of English Names and Implications for Classroom Practice." Theory and Practice in Language Studies 2, no. 3: 469-474.

Chik, Alice. 20I0. "Nongbao, I Am a Shanghai Noenoe. How Do I Claim My Shanghaineseness?" In Language and Culture: Reflective Narratives and the Emergence of Identity, edited by David Nunan and Julie Choi, 58-65. New York: Routledge.

Constantine, Madonna G., Tina Q. Richardson, Eric M. Benjamin, and John W. Wilson. I998. "An Overview of Black Racial Identity Theories: Limitations and Considerations for Future Theoretical Conceptualizations." Applied and Preventive Psychology 7: 95-99.

Cross Jr, William E. I97I. “The Negro-to-Black Conversion Experience.” Black World 20, no. 9: I3-27.

Cross Jr, William E. 1978. "The Thomas and Cross Models of Psychological Nigrescence: A Literature Review." Journal of Black Psychology 5, no. I: I3-3I.

Cross, William E., Jr. I995. “The Psychology of Nigrescence: Revising the Cross Model." In Handbook of Multicultural Counseling, edited by Joseph G. Ponterotto, J. Manuel Casas, Lisa A. Suzuki, and Charlene M. Alexander, 93-I22. Thousand Oaks, CA: Sage.

Crossley, Michele L. 2000. "Narrative Psychology, Trauma and the Study of Self/Identity." Theory and Psychology Io, no. 4: 527-546.

Dunne, Joseph. I995. "Beyond Sovereignty and Deconstruction: The Storied Self." Philosophy and Social Criticism 2I: I37-I 57 .

Edge, Julian. 2010. "Elaborating the Monolingual Deficit." In Language and Culture: Reflective Narratives and the Emergence of Identity, edited by David Nunan and Julie Choi, 89-96. New York: Routledge.

Edwards, Rachel. 2006. "What's in a Name? Chinese Learners and the Practice of Adopting 'English' Names." Language, Culture and Curriculum I9, no. I: 90-103.

Emmelhainz, Celia. 20I2. "Naming a New Self: Identity Elasticity and Self-Definition in Voluntary Name Changes." Names 60, no. 3: 156-165.

Fitzgerald, M. 200I. "Gaining Knowledge of Culture during Professional Education.” In Practice Knowledge and Expertise in the Health Professions, edited by Joy Higgs and Angie Titchen, I49-156. Melbourne: ButterworthHeinemann.

Fuller-Rowell, Thomas E., Anthony D. Ong, and Jean S. Phinney. 20I3. "National Identity and Perceived Discrimination Predict Changes in Ethnic Identity Commitment: Evidence from a Longitudinal Study of Latino College Students." Applied Psychology 62, no. 3: 406-426.

Goldstein, Joshua, R., and Guy. Stecklov. 2016. "From Patrick to John F.: Ethnic Names and Occupational Success in the Last Era of Mass Migration." American Sociological Review 8I, no. I: 85-106.

Gunn, Janet Varner. 1982. Autobiography: Towards a Poetic of Experience. Philadelphia, PA: University of Pennsylvania Press.

Hannah, Soong. 2015. Transnational Students and Mobility: Lived Experiences of Migration. Oxford: Routledge.

Harrison, K. David.I999. "Naming Practices and Ethnic Identity in Tuva." Proceedings of the Chicago Linguistic Society 35, no. 2: I-II. The Panels.

Heffernan, Kevin. 20I0. "English Name Use by East Asians in Canada: Linguistic Pragmatics or Cultural Identity?" Names 58, no. I: $24-36$.

Henry, Eric, S. 20I2. "When Dragon Met Jasmine: Domesticating English Names in Chinese Social Interaction." Canadian Anthropology Society 54, no. I: I07-II7.

Highlen, Pamela S., Amy L. Reynolds, Eve M. Adams, Tricia C. Hanley, Linda J. Myers, Chikako Cox, and Suzette Speight. I988. "Self-Identity Development Model of Oppressed People: Inclusive Model for All?” Paper presented at the American Psychological Association Convention. Atlanta, GA.

Hughes, H. and Kirsty Williamson, Annemaree Lloyd. 2007. "Critical Incident Technique.” In Exploring Methods in Information Literacy Research, edited by Suzanne Lipu, Kirsty Williamson, and Annemaree Lloyd, 49-66. Wagga Wagga, N.S.W, Charles Sturt University.

Kim, Jean. I98I. "The Process of Asian-American Identity Development: A Study of Japanese American Women's Perceptions of Their Struggle to Achieve Positive Identities." Doctoral dissertation, University of Massachusetts.

Lave, Jean, and Etiene Wenger. 1991. Situated Learning: Legitimate Peripheral Participation. Cambridge: Cambridge University Press.

Li, David C. S. I997. "Borrowed Identity: Signaling Involvement with a Western Name." Journal of Pragmatics 28: 489-5I3.

May, Stephen. 200I. Language and Minority Rights: Ethnicity, Nationalism and the Politics of Language. Harlow: Pearson Education.

McPherron, Paul. 2009. "My Name is Money': Name Choices and Global Identifications at a South-Chinese University." Asian Pacific Journal of Education 29, no. 4: 52I-536.

Pennycook, Alastair. 2004. "Performativity and Language Studies." Critical Inquiry in Language Studies I, no. I: I-I9. 
Phinney, Jean, S. 1989. "Stages of Ethnic Identity Development in Minority Group Adolescents." The Journal of Early Adolescence 9, no. I/2: 34-49.

Phinney, Jean, S. I990. "Ethnic Identity in Adolescents and Adults: Review of Research.” Psychological Bulletin Io8, no. 3: 499-5I4.

Pietikäinen, Sari, and Hannele Dufva. 2006. "Voices in Discourses Dialogism, Critical Discourse Analysis and Ethnic Identity." Journal of Sociolinguistics Io, no. 2: 205-224.

Piller, Ingrid. 2002. Bilingual Couple Talks: The Discursive Construction of Hybridity. Amsterdam: Benjamins.

Quaglia, Rocco, Claudio Longobardi, Manuela Mendola, and Laura Elvira Prino. 20I6. "Names in Psychological Science: Investigating the Processes of Thought Development and the Construction of Personal Identities." Integrative Psychological and Behavioral Science 50: 277-295.

Riessman, Catherine Kohler. 200I. "Analysis of Personal Narratives." In Handbook of Interview Research, edited by Jaber F.. Gubrium and James A. Holstein, 695-710. Thousand Oaks, CA: Sage.

Rosenblum, Karen E., David W. Haines, and Hyunyoung Cho. 2016. "Where Are We, When Are We, and Who Are We to Each Other? Connectedness and the Evolving Meanings of International Education." In International Student Connectedness and Identity, edited by Ly Tran and Catherine Gomes, I69-I83. Singapore: Springer.

Ruiz, Aureliano Sandoval. I999. "Ethnic Identity: Crisis and Resolution." Journal of Multicultural Counseling \& Development I8, no. I: $29-40$.

Sandelowski, Margarete. I99I. “Telling Stories: Narrative Approaches in Qualitative Research.” Journal of Nursing Scholarship 23, no. 3: I6I-I66.

Sercombe, Peter, Tony Young, Ming Dong, and Lin Lin. 20I4. "The Adoption of Non-Heritage Names among Chinese Mainlanders." Names 62, no. 2: 65-75.

Tournier, Paul. 1975. The Naming of Persons. New York: Harper.

Yoon, Eunju, Kristen Adams, Angela Clawson, Hanna Chang, Shruti Surya, and Gihane Jérémie-Brink. 20I7. "East Asian Adolescents' Ethnic Identity Development and Cultural Integration: A Qualitative Investigation.” Journal of Counseling Psychology 64, no. I: 65-79.

\section{Notes on contributor}

Xing $\mathrm{Xu}$ is a lecturer at Sichuan International Studies University, China, and a PhD candidate at the University of Newcastle, Australia. Her areas of interest are identity theory, cross-cultural adaptation, language development, and cultural studies.

Correspondence to: Xing Xu, OB85, Academic Office Block, University Drive, University of Newcastle, Callaghan NSW 2308, Australia.Email:xing.xu@uon.edu.au 